\title{
Advanced Methods for the Analysis of Altered Pre-mRNA Splicing in Yeast and Disease
}

DOI:

10.1007/978-1-4939-9736-7_8

\section{Document Version}

Accepted author manuscript

Link to publication record in Manchester Research Explorer

\section{Citation for published version (APA):}

O'Keefe, R. T., \& Thomas, H. (2019). Advanced Methods for the Analysis of Altered Pre-mRNA Splicing in Yeast and Disease. Methods in molecular biology (Clifton, N.J.), 2049, 131-140. https://doi.org/10.1007/978-1-49399736-7_8

\section{Published in:}

Methods in molecular biology (Clifton, N.J.)

\section{Citing this paper}

Please note that where the full-text provided on Manchester Research Explorer is the Author Accepted Manuscript or Proof version this may differ from the final Published version. If citing, it is advised that you check and use the publisher's definitive version.

\section{General rights}

Copyright and moral rights for the publications made accessible in the Research Explorer are retained by the authors and/or other copyright owners and it is a condition of accessing publications that users recognise and abide by the legal requirements associated with these rights.

\section{Takedown policy}

If you believe that this document breaches copyright please refer to the University of Manchester's Takedown Procedures [http://man.ac.uk/04Y6Bo] or contact uml.scholarlycommunications@manchester.ac.uk providing relevant details, so we can investigate your claim.

\section{OPEN ACCESS}




\title{
Advanced methods for the analysis of altered pre-mRNA splicing in yeast and disease
}

\author{
Huw B. Thomas and Raymond T. O’Keefe
}

\section{Abstract}

Splicing of pre-messenger RNA (pre-mRNA) transcripts is a fundamental process in all eukaryotes that provides a mechanism of increasing the proteomic diversity within a cell that can be tightly regulated in a dynamic manner. Whilst constitutive and alternative splicing are necessary for the correct development and regulation of cells/organisms, aberrant splicing is now associated with an increasingly varied number of human diseases, such as neurological and developmental diseases, and cancer. Studies of splicing mechanisms and regulation are often achieved in non-human model organisms such as yeast. Yeasts possess homologs to many of the core spliceosome components of higher organisms, including humans, and as such yeast are now a well-established model organism for understanding how differential splicing of transcripts can alter the phenotype of a cell or organism. Here we describe methods to investigate premRNA splicing in yeast cells using modern RNA-Seq technology and bioinformatics software. Details of traditional validation methods are also described.

Key words pre-mRNA splicing, spliceosome, RNA-Seq, yeast

Running head: pre-mRNA splicing

\section{Introduction}

In eukaryotic cells, the identification and removal of intervening sequences from a newly transcribed pre-mRNA is a fundamental prerequisite of protein translation. Splicing of pre-mRNA transcripts is a highly regulated process catalysed by the spliceosome, a large ribonucleoprotein complex composed of five small nuclear ribonucleoproteins (snRNPs) and numerous other proteins [1]. Tightly regulated assembly and temporal rearrangement of the core components of the spliceosome lead to accurate splicing of pre-mRNA which can be dynamically regulated during development and in response to changing environmental conditions.

Much of the research into spliceosome structure, splicing-mechanisms and regulation has been achieved in yeast. Many of the core spliceosome components are homologous between yeast and higher eukaryotes, mirroring the level of structural complexity seen in human splicing. Fewer than $5 \%$ of yeast genes are subject to splicing but these spliced genes are highly expressed and the vast 
majority of these genes are comprised of two exons separated by a single intron. This simplicity makes yeast an attractive system for detailed analysis of both constitutive and alternative splicing.

Modern advances in RNA sequencing (RNA-Seq) have led to a huge increase in sequencing speed, fidelity and ease of use. Coupled with an exponential fall in cost, this has resulted in a dramatic increase in RNA-Seq use and ubiquity among both basic and clinical research endeavours [2,3]. A major advantage of RNA-Seq is the ability to interrogate the data in several ways reliant only on the downstream bioinformatics software used. For example, a single RNA-Seq dataset can be used to provide information on gene expression, transcriptional start sites, exon usage, and allele frequency, each with specific analytical software requirements, but all taking mapped RNA-Seq data as a starting input.

For studies of alternative splicing, many bespoke software packages are available which provide statistical quantification of splicing events between experimental conditions. However, a simpler process is to directly compare the expression levels of intron portions of transcripts with their surrounding exon portions. This comparison allows direct analysis of the levels of intron retention within a transcript under different conditions.

An increasing number of human diseases and disorders are being associated with mechanisms of splicing and components of the spliceosome [4-8]. Often despite mutations in core spliceosomal components that make up one specific snRNP particle, the resulting characteristics of the disorders are varied with very distinct or only partially overlapping phenotypes. For example, EFTUD2/SNU114, TXNL4A/DIB1, SNRNP200/BRR2 and PRPF8/PRP8 are all proteins associated with the U5 snRNP [9-11]. However, mutations in EFTUD2 and TXNL4A cause craniofacial disorders $[4,5]$ whereas mutations in SNRNP200 and PRPF8 cause degenerative retinal disease $[12,13]$. Understanding how and why the genetic variations observed amongst ubiquitous spliceosome genes can lead to the scope of different diseases and disorders is of great value. However, in many cases access to patient samples is limited and alternative methods and model organisms must be used.

Well-established molecular techniques in yeast enable the engineering of yeast strains that closely resemble the genetic mutations seen in a disease/disorder of interest. These methods can be used as a prerequisite to analysis of global splicing patterns using RNA-Seq. For example, using site-directed mutagenesis and a plasmid shuffle technique [14] a variant form of a spliceosome gene can be expressed as the sole allele in a haploid yeast strain, thus investigating the effect of the mutation on global splicing fidelity.

Alternatively, replacing the promoter of a spliceosomal gene of interest with an inducible promoter allows the temporal knock-down in expression of a target gene [15]. This method allows characterisation of genes most sensitive to reduced levels of core spliceosome components and models several developmental disorders where reduced expression (haploinsufficiency) of core spliceosome components is predicted as the causative mechanism [16]. 
Herein we describe the methods required to undertake analysis of such yeast strains using modern RNA-Seq techniques to quantify precisely the exonic and intronic portions of the yeast transcriptome. Knowing how the expression of introns and exons alter over time can inform on not only the splicing efficiency for that transcript but also if increased retention of introns affects the stability of the overall transcript by leading to increased targeting of transcript by nonsense mediated decay pathways. 


\section{Materials}

\subsection{Yeast culture}

2.1.1 YPD medium

Yeast extract $(1 \% \mathrm{w} / \mathrm{v})$; Peptone $(2 \% \mathrm{w} / \mathrm{v})$; Dextrose $(2 \%$ $\mathrm{w} / \mathrm{v}$ )

2.1.2 YPGal medium

Yeast extract $(1 \% \mathrm{w} / \mathrm{v})$; Peptone $(2 \% \mathrm{w} / \mathrm{v})$; Galactose $(2 \%$ $\mathrm{w} / \mathrm{v}$ )

\subsection{RNA extraction}

2.2.1 RiboPure $^{\mathrm{TM}}$ RNA purification kit, yeast (Ambion ${ }^{\circledR}$ Thermo Fisher)

2.2.2 RNaseZAP ${ }^{\mathrm{TM}}$

\subsection{Bioinformatic analysis (software and reference files)}

2.3.1 FastQ Screen

2.3.2 FastQC [17]

2.3.3 Trimmomatic [18]

2.3.4 STAR: Ultrafast universal RNA-Seq aligner [19]

2.3.5 sacCer3 genome assembly for S.cerevisiae (April 2011)

2.3.6 HTSeq [20]

2.3.7 DeSeq2 [21]

2.3.8 Annotated yeast reference file (S.cerevisiae.gff)

2.3.9 GraphPad Prism

2.3.10 Multiple experiment viewer (MeV) [22]

\section{4 cDNA synthesis}

2.4.1SuperScript ${ }^{\mathrm{TM}} \quad$ IV $\quad$ First-Strand synthesis system (ThermoFisher): 5x SuperScript IV buffer; DTT (0.1 M); dNTPs (10 $\mathrm{mM}$ ); Ribonuclease inhibitor (e.g. RNasin or RNAseOut); E.coli RNAseH (5000 U/mL)

\subsection{PCR amplification}

Phusion High-Fidelity DNA polymerase; 5x Phusion High-Fidelity buffer; dNTPs (10 mM); Forward validation primer $(10 \mu \mathrm{M})$; Reverse validation primer $(10 \mu \mathrm{M})$; Nuclease-free water (see Note 1)

\subsection{Agarose gel electrophoresis}

2.6.1 Agarose

2.6.2 1X Tris acetate EDTA Buffer (TAE) pH 8.5: Tris base $40 \mathrm{mM}$; EDTA $2 \mathrm{mM}$; Acetic acid $20 \mathrm{mM}$

2..6.3 SafeView DNA stain (NBS biologicals) 


\section{Methods}

\subsection{Yeast culture}

Incubate yeast strain(s) in an appropriate volume of growth medium, for example YPD (or YPGal if using a galactoseinducible strain) and incubate at $30^{\circ} \mathrm{C}$ with constant shaking (see Note 2).

\subsection{RNA isolation and preparation}

1. Follow manufacturer's recommended protocol for purification of RNA from yeast cultures grown under your specific conditions using the RiboPure ${ }^{\mathrm{TM}}$ yeast RNA isolation kit. For best results: isolate cells during exponential growth phase and use close to maximum recommended number of cells $\left(3 \times 10^{8}\right)$ per filter cartridge (see Notes 3 and 4). Include optional DNase treatment step to ensure no contaminating DNA is carried forward into downstream applications.

2. Quantify purity of extracted RNA by measuring the $260 / 280$ $\mathrm{nm}$ wavelength ratio using a spectrophotometer (i.e. NanoDrop ${ }^{\mathrm{TM}}$ ) (see Note 5).

3. Quantify the integrity of the RNA using an automated electrophoresis machine such as the Agilent Bioanalyser or TapeStation (see Note 6).

4. RNA is now ready for enrichment and library preparation prior to being sequenced on the Illumina platform (core facility or external contractor) (see Note 7).

\subsection{Bioinformatic analyses}

5. Run raw sequencing data (typically in .FASTQ format) through quality control analysis software such as FastQ Screen and FastQC to highlight any sample contamination and low quality sequencing (respectively).

6. Trim low sequencing quality bases from the 3' end of reads using Trimmomatic (see Note 8).

7. Map reads to appropriate reference genome assembly (for example UCSC's sacCer3 assembly for S.cerevisiae) using STAR and appropriate default settings (see Note 9).

8. Quantify the mapped reads using htseq-count. For alternative splicing analysis two separate read counts will need to be performed. The first quantifying all reads that fall within coding (exonic) regions of the genome and the second 
quantifying all reads that fall within intronic regions. Use recommended/default settings and an appropriately annotated reference sequence to define coding and non-coding regions (for example S.cerevisiae.gff available from yeastgenome.org).

9. Calculate and quantify differential expression of genes, transcripts, exons or introns using DeSeq2 (see Note 10)

10. Once a quantified value for each intron and/or exon of interest has been achieved, the data can be visually represented in a variety of way which best suits the aim of the specific study. A common method of representing global patterns of expression is to use hierarchical clustering of quantified expression values and visualisation in a heatmap image. Use Multiple experiment Viewer (MeV) to perform hierarchal clustering using default settings, an example of which is shown in Fig. 1. Direct comparisons of intron vs exon expressions for individual transcripts of interest can be achieved using dual y-axis graphs using graphical/statistical analysis software such as GraphPad/Prism. If looking at alternative splicing at multiple time points then comparison of intron vs exon expression over time can reveal several different patterns of expression relating to splicing efficiency and transcript stability. Fig. 2 gives examples of the patterns of expression seen between exon and intron portions of transcripts when spliceosome function is disrupted by temporal knock-down of a core spliceosome component.

\subsection{Data validation by RT-PCR}

11. Using purified RNA collected from step 4, convert up to $5 \mu \mathrm{g}$ of yeast RNA for each experimental condition to cDNA using the SuperScript IV First-Strand synthesis system following the manufacturer's recommended protocol (see Note 11).

12. Anneal $1 \mu \mathrm{L}$ of primers ( $50 \mu \mathrm{M}$ Oligo $\mathrm{d}(\mathrm{T})_{20}, 50 \mathrm{ng} / \mu \mathrm{L}$ random hexamers or $2 \mu \mathrm{M}$ gene specific primers may be used) to RNA by mixing RNA with $1 \mu \mathrm{L}$ of primers and $1 \mu \mathrm{L}$ of $10 \mathrm{mM}$ dNTPs and incubate at $65^{\circ} \mathrm{C}$ for 5 min before cooling on ice. 
13. Add $1 \mu \mathrm{L}$ SuperScript IV reverse transcriptase and $4 \mu \mathrm{L}$ of $5 \mathrm{X}$ buffer to $1 \mu \mathrm{L}$ of DTT (100 mM) and $1 \mu \mathrm{L}$ RNase inhibitor (e.g. RNasin ${ }^{\circledR}$ ). Incubate sample at $50-55^{\circ} \mathrm{C}$ for $10 \mathrm{~min}$ before stopping the reaction by incubating sample at $80^{\circ} \mathrm{C}$ for a further $10 \mathrm{~min}$. Following the reaction, any left-over RNA may be removed by addition of $1 \mu \mathrm{L}$ of E. coli RNAseH (5000U/ $\mu \mathrm{L})$ and incubating at $37^{\circ} \mathrm{C}$ for $20 \mathrm{~min}$.

14. Newly synthesised cDNA from step 11 can be stored at $-20^{\circ} \mathrm{C}$ or used immediately for PCR amplification.

15. Using primers specifically designed to validate results from bioinformatics analysis, perform a standard PCR reaction using the Phusion High-fidelity DNA polymerase (see Note 12). Mix $4 \mu \mathrm{L}$ of $5 \mathrm{X}$ Phusion-HF buffer with $0.4 \mu \mathrm{L}$ dNTPs $(10 \mu \mathrm{M}), 0.2$ $\mu \mathrm{L}$ Phusion DNA polymerase, $1 \mu \mathrm{L}$ of each validation primer (10 and add to $1 \mu \mathrm{L}$ of cDNA from step 10 (20-100 ng/ $\mu \mathrm{L})$. Add nuclease-free water to the reaction up to a volume of $20 \mu \mathrm{L}$ (see Note 1) and incubate in a thermal cycler using the following protocol:

1. $98^{\circ} \mathrm{C}$ for $30 \mathrm{sec}$

2. $98^{\circ} \mathrm{C}$ for $10 \mathrm{sec}$

3. Calculated annealing temperature for $20 \mathrm{sec}$ (see Note 13)

4. $72^{\circ} \mathrm{C}$ for $15-30 \mathrm{sec} / \mathrm{kb}$

5. Repeat steps 2-4 for 34 cycles

6. $72^{\circ} \mathrm{C}$ for $10 \mathrm{~min}$

16. Analyse amplified PCR product(s) by running on a suitable percentage agarose gel. For example: for a PCR product 2001000 base pairs, use $1 \% \mathrm{w} / \mathrm{v}$ agarose in $1 \mathrm{x}$ TAE buffer plus 0.01\% SafeView DNA-stain. Using a BioRad Mini-Sub Cell GT gel electrophoresis chamber run the gel at a constant voltage of 65-75 $\mathrm{V}$ for 40-60 min (other electrophoresis equipment may require different voltage and/or running time).

15. Image gel using a UV-image station

16. Quantify density of bands and calculate ratio of spliced transcript vs unspliced transcript and compare with ratio quantified by RNA-Seq. 


\section{Notes}

1.

Use a cellulose nitrate filter unit with $0.2 \mu \mathrm{m}$ pore size to remove potential nuclease contamination from deionised water. This avoids the need to use DEPC treatment.

2.

If comparing splicing between strains with different levels of temporal knock-down of a core spliceosome component e.g. $4 \mathrm{~h}$ knock-down vs $8 \mathrm{~h}$ knock-down then starting OD of yeast cultures should be altered such that final ODs of strains are as similar as possible at the point of RNA extraction despite different incubation times. In addition, at least 3 replicates should be processed to ensure consistency and accuracy of downstream RNA-Seq data.

3.

RNA is much less stable than DNA and subject to degradation by RNases present in the environment. Therefore, care should be taken to eliminate risk of degradation by firstly treating the working area and instruments (e.g. pipettes) with an anti-RNase decontaminant such as RNaseZap ${ }^{\mathrm{TM}}$. Secondly, extracted RNA should be kept on ice between steps, wherever possible, and finally, for best results, isolated RNA should be snap frozen (with liquid nitrogen) and stored at $-80^{\circ} \mathrm{C}$ (unless being used for downstream procedures immediately).

4.

If higher final concentrations of RNA are required the final elution step of the RiboPure ${ }^{\mathrm{TM}}$ protocol can be repeated with the original eluted flow-through to increase the yield of RNA from the filter cartridge without having to increase the final volume. For example $2 \times 50 \mu$ L elution steps using preheated elution solution, followed by a third elution with the collected $100 \mu \mathrm{L}$ elute.

5.

Success of subsequent RNA-Seq and quality of downstream data is heavily dependent on the purity and integrity of the original RNA sample. Purity of the 
RNA sample can be determined by NanoDrop ${ }^{\text {TM }}$ quantification of the $260 / 280 \mathrm{~nm}$ wavelength ratio, with a ratio lower or higher than 2.0 indicating potential contamination with solvents (e.g. Phenol from extraction kit) and/or protein (from original cell culture).

6.

Integrity of RNA is traditionally measured on a scale of 1-10 with an RNA Integrity Number (RIN) value of 10 indicating the highest integrity possible. A value of 8 or above is generally considered appropriate for RNA-Seq experiments, with decreasing values indicating the RNA sample has degraded during the isolation process or is of low starting quality (e.g. from dead/senescent cells). Whilst good RNA-Seq data can be achieved from low RIN RNA, analysis of alternative/aberrant splicing events demands the highest read depth and read coverage possible.

7.

Several options are often available in terms of methods for enrichment (such as poly-A selection or rRNA depletion) and library preparation (such as single or paired-end sequencing). Typically, poly-A selection provides excellent enrichment of the mRNA population, whilst paired-end sequencing provides the greatest amount of data with a higher rate of uniquely mapped reads, an important consideration for splice variant analysis.

8.

Removing bases with low sequencing quality from the 3 ' ends of reads can improve the success rate of subsequently mapping reads to the reference genome. This step can also be used to remove any adapter or barcode sequences added during library preparation that would interfere with the mapping process.

9.

For best results, use only reads that map uniquely to the reference sequence. For paired-end libraries, reads should be mapped as pairs.

10.

Software such as DeSeq2 take the quantified mapped reads and calculates the log fold change and statistical significance of any differential expression of a defined 
sequence (for example an exon, intron or coding sequence) between two experimental conditions. This analysis provides an accurate method of quantifying the level of intron retention or splicing efficiency of a transcript under a given experimental condition.

11.

Depending on final elution volume in the final step of RNA isolation, often the RNA concentration will not need further dilution before beginning cDNA synthesis $(<500 \mathrm{ng} / \mu \mathrm{L})$. If multiple samples are to be processed in parallel, normalise all samples at this point by using an equal amount of starting RNA for each cDNA synthesis reaction. Thus, for the least concentrated sample no water need be added (i.e. using the maximum $11 \mu \mathrm{L}$ of RNA), whilst all other samples will be made up to an $11 \mu \mathrm{L}$ volume using a dilution of RNA and water to achieve an equal starting amount of RNA per $20 \mu \mathrm{L}$ cDNA synthesis reaction.

12.

For validating alternative splicing events, primers should be designed to amplify between two exons separated by an intron, such that two different PCR products could be produced, one representing unspliced transcripts (containing the intron sequence), and a second population of a shorter product representing spliced transcripts. Typically an unspliced product size of $300-500 \mathrm{bp}$ with a shorter (spliced) product by least $100 \mathrm{bp}$ is desirable when designing primers.

13. Use a Tm calculator specifically for the Phusion Highfidelity DNA polymerase to calculate the optimal annealing temperate for the validation primers. 


\section{References}

1. Will CL, Lührmann R (2011) Spliceosome structure and function. TL - 3. Cold Spring Harb Perspect Biol 3 VN-re:1-23 . doi:

10.1101/cshperspect.a003707

2. Wright HL, Thomas HB, Moots RJ, Edwards SW (2013) RNA-Seq Reveals Activation of Both Common and Cytokine-Specific Pathways following Neutrophil Priming. PLoS One 8: . doi: 10.1371/journal.pone.0058598

3. Wright HL, Thomas HB, Moots RJ, Edwards SW (2014) Interferon gene expression signature in rheumatoid arthritis neutrophils correlates with a good response to TNFi therapy. Rheumatol (United Kingdom) 54:188-193 . doi: 10.1093/rheumatology/keu299

4. Wieczorek D, Newman WG, Wieland T, et al (2014) Compound Heterozygosity of Low-Frequency Promoter Deletions and Rare Loss-ofFunction Mutations in TXNL4A Causes Burn-McKeown Syndrome. Am J Hum Genet 95:698-707 . doi: 10.1016/j.ajhg.2014.10.014

5. Lines MA, Huang L, Schwartzentruber J, et al (2012) Haploinsufficiency of a spliceosomal GTPase encoded by EFTUD2 causes mandibulofacial dysostosis with microcephaly. Am J Hum Genet 90:369-377 . doi: 10.1016/j.ajhg.2011.12.023

6. Bacrot S, Doyard M, Huber C, et al (2015) Mutations in SNRPB, encoding components of the core splicing machinery, cause cerebro-costomandibular syndrome. Hum Mutat 36:187-190 . doi: 10.1002/humu.22729

7. Tan Q, Yalamanchili HK, Park J, et al (2016) Extensive cryptic splicing upon loss of RBM17 and TDP43 in neurodegeneration models. Hum Mol Genet 25:5083-5093 . doi: $10.1093 / \mathrm{hmg} / \mathrm{ddw} 337$

8. Chen K, Xiao H, Zeng J, et al (2017) Alternative splicing of EZH2 pre-mRNA by SF3B3 contributes to the tumorigenic potential of renal cancer. Clin Cancer Res 23:3428-3441 . doi: 10.1158/1078-0432.CCR-16-2020

9. Frazer LN, Nancollis V, O'Keefe RT (2008) The role of Snu114p during premRNA splicing. Biochem Soc Trans 36:551-3 . doi: 10.1042/BST0360551

10. Grainger RJ, Beggs JD (2005) Prp8 protein: At the heart of the spliceosome. RNA 11:533-557 . doi: 10.1261/rna.2220705

11. Hahn D, Beggs JD (2010) Brr2p RNA helicase with a split personality: insights into structure and function: Figure 1. Biochem Soc Trans 38:1105-1109 . doi: 10.1042/BST0381105

12. Zhao C, Bellur DL, Lu S, et al (2009) Autosomal-Dominant Retinitis Pigmentosa Caused by a Mutation in SNRNP200, a Gene Required for Unwinding of U4/U6 snRNAs. Am J Hum Genet 85:617-627 . doi: 10.1016/j.ajhg.2009.09.020

13. Towns K V., Kipioti A, Long V, et al (2010) Prognosis for splicing factor PRPF8 retinitis pigmentosa, novel mutations and correlation between human and yeast phenotypes. Hum Mutat 31:1361-1376 . doi: 10.1002/humu.21236

14. O'Keefe RT, Beggs JD (2012) Yeast Genetics to Investigate the Function of Core Pre-mRNA Splicing Factors. In: Alternative pre-mRNA Splicing: Theory and Protocols. pp 428-436 
15. Janke C, Magiera MM, Rathfelder N, et al (2004) A versatile toolbox for PCR-based tagging of yeast genes: new fluorescent proteins, more markers and promoter substitution cassettes. Yeast 21:947-962 . doi:

10.1002/yea.1142

16. Lehalle D, Wieczorek D, Zechi-Ceide RM, et al (2015) A review of craniofacial disorders caused by spliceosomal defects. Clin Genet 88:405415 . doi: $10.1111 /$ cge. 12596

17. Andrews S (2010) FastQC: A quality control tool for high throughput sequence data. babraham Bioinforma 1

18. Bolger AM, Lohse M, Usadel B (2014) Trimmomatic: A flexible trimmer for Illumina sequence data. Bioinformatics 30:2114-2120 . doi: 10.1093/bioinformatics/btu170

19. Dobin A, Davis CA, Schlesinger F, et al (2013) STAR: Ultrafast universal RNA-seq aligner. Bioinformatics 29:15-21 . doi:

10.1093/bioinformatics/bts635

20. Anders S, Pyl PT, Huber W (2015) HTSeq-A Python framework to work with high-throughput sequencing data. Bioinformatics 31:166-169 . doi: 10.1093/bioinformatics/btu638

21. Love MI, Anders S, Huber W (2014) Differential analysis of count data - the DESeq2 package

22. Howe EA, Sinha R, Schlauch D, Quackenbush J (2011) RNA-Seq analysis in MeV. Bioinformatics 27:3209-3210 . doi: 10.1093/bioinformatics/btr490 


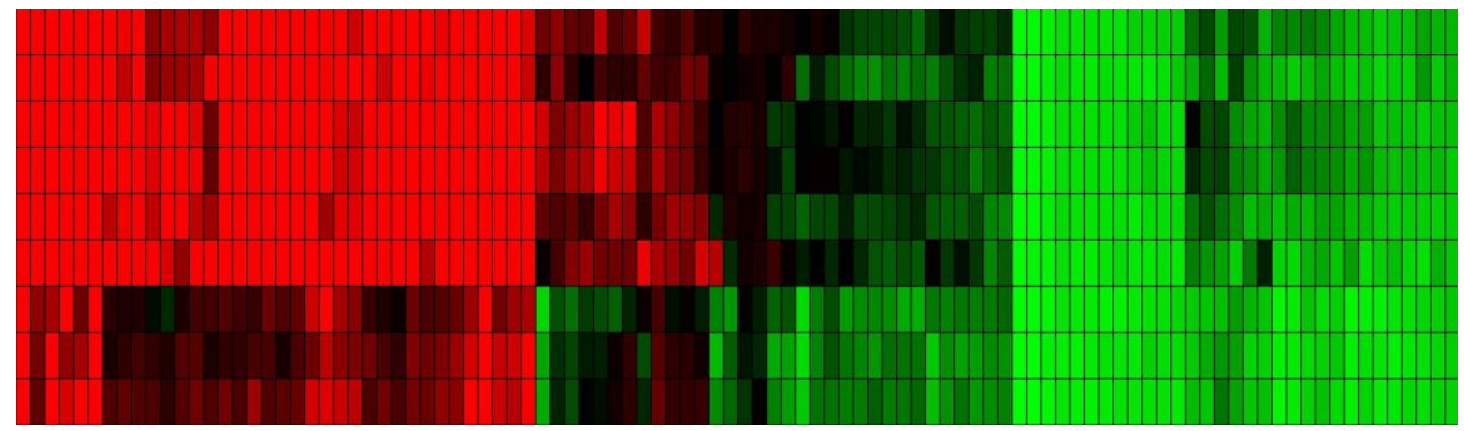

Fig. 1 Example heat-map of transcript intron expression levels under different conditions. Red represents high expression, black represents moderate expression, and green represents low/no expression. Each column represents the single intron region of a transcript. Each of the 9 rows represents a separate experiment with different experimental conditions. Heat-map was produced by Multiple experiment Viewer $(\mathrm{MeV})$ using normalised expression values for each intron region and performing hierarchical clustering of values [22]. 

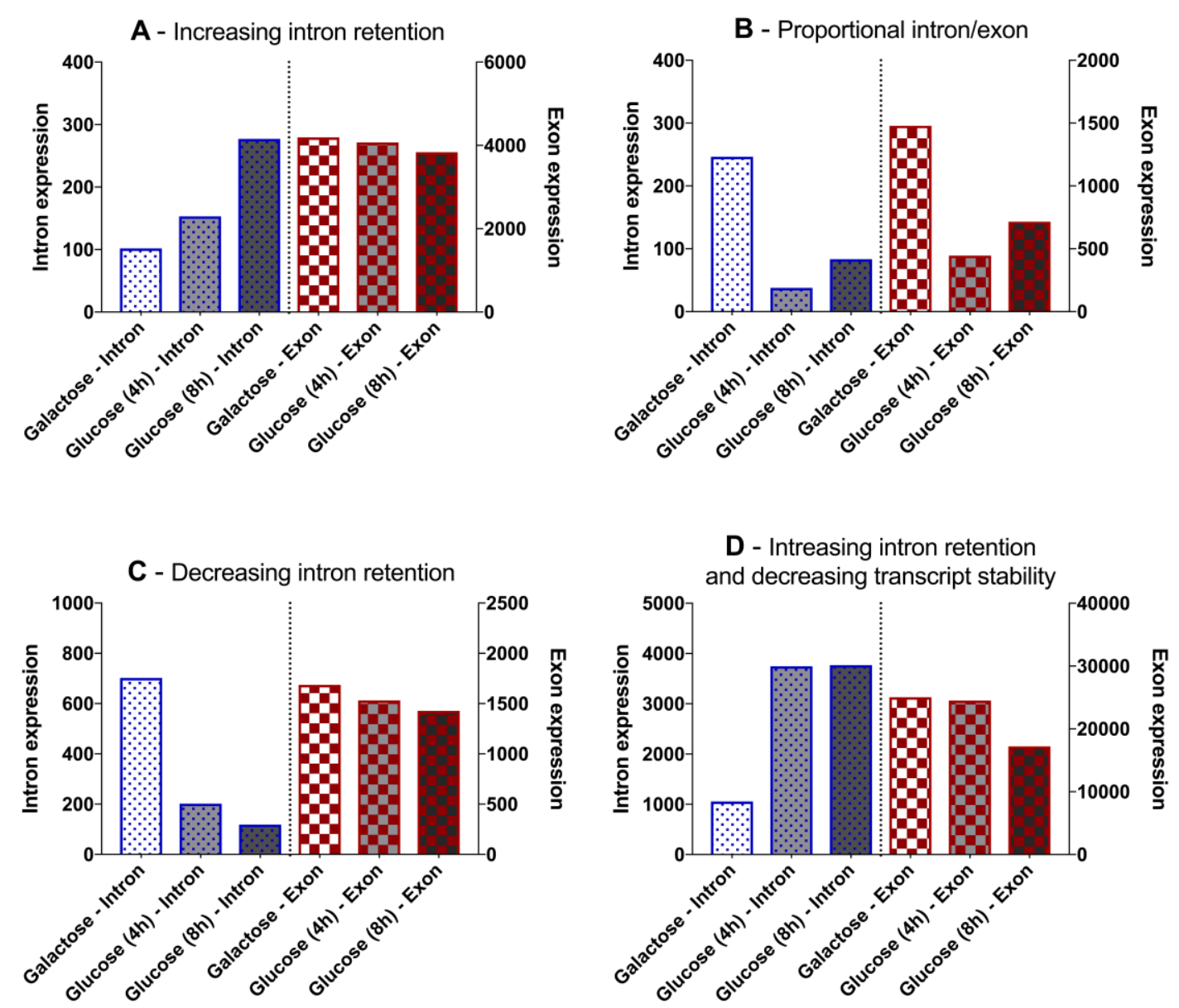

Fig. 2 Example graphs showing intron (blue bars) and exon expression (red bars) for a given transcript in yeast following temporal reduction in a core spliceosome component. Galactose condition represents normal expression of core spliceosome component, glucose conditions represent conditions of reduced expression of core spliceosome component for 4 and $8 \mathrm{~h}$. Data quantified by RNA-Seq. A. Expression of introns increases with time whilst exon expression remains constant - increased intron retention. B. Both intron and exon expression levels alter over time proportionally - No change in splicing efficiency. C. Decrease in intron expression whilst exon expression levels stay constant - Increase in transcript splicing. D. Increase in intron expression and corresponding decrease in exon expression - Increase in intron retention and transcript degradation. 

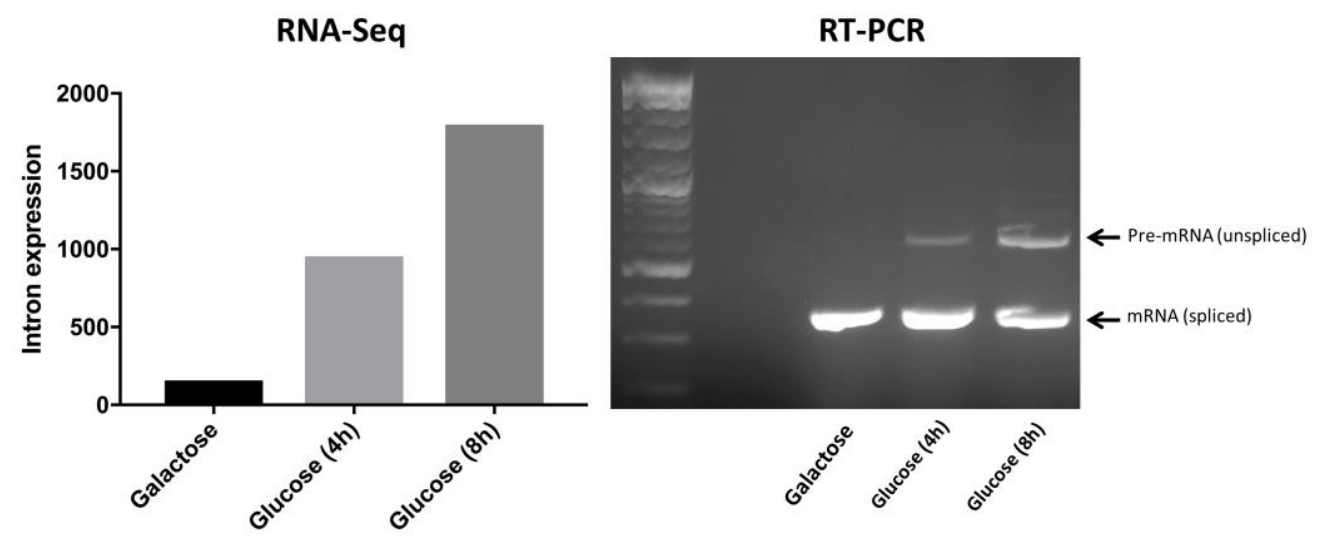

Fig. 3 Example of RT-PCR validating results for an RNA-Seq experiment. Left panel shows expression values for an intron portion of a transcript following knockdown of a spliceosomal component for $4 \mathrm{~h}$ and $8 \mathrm{~h}$. Right-hand panel shows RT-PCR using validating primers to identify a corresponding increase in larger fragment relating to transcript where intron portion is retained in the pre-mRNA. 